\title{
IMPROVING THE QUALITY OF FIRE RISK ASSESSMENT BY USING EVACUATION SIMULATION SOFTWARE
}

\author{
Srđan Popova , Mirjana Laban ${ }^{\mathrm{a}}$, Suzana Vukoslavčevića ${ }^{\mathrm{a}}$, Slobodan Šupića ${ }^{\mathrm{a}}$, Sanja Milanko ${ }^{\mathrm{a}}$ \\ ${ }^{a}$ University of Novi Sad, Faculty of Technical Sciences, Novi Sad, Serbia
}

\begin{abstract}
The time required for evacuation of all persons who could be present in the building during a fire event depends on a number of factors, some of which are very difficult to predict. In order to achieve more realistic evaluation of the evacuation process, engineers are increasingly turning towards evacuation computer models. These evacuation models could help reduce the consequences related to a wide range of adverse events, such as fires, by indicating critical points on the evacuation paths. At the same time, simulation tools can be used for exploring how certain changes within the real system could affect the efficiency of evacuation and fire safety of the building even before they are implemented. The computer model for the Amphitheatres in FTS in Novi Sad has been created using simulation software - Pathfinder, based on SRPS TP 21. This paper presents contribution of evacuation software models to the quality of fire safety assessment.
\end{abstract}

Keywords: evacuation, fire risk, calculation, simulation, modelling

\section{INTRODUCTION}

The first and most important aim of fire safety is to protect people's lives. Within public buildings, fire is recognised as a major threat to the activities that are being carried out inside the building. Also, considering the complex built environment of public buildings and large number of occupants, as well as a large quantity of combustible materials in these facilities, the humans' live protection is surely a challenging issue.

Institutions, staff and students have limited awareness of the range of risks to which they and their environment are exposed (Helsloot et al., 2006). Most institutions organize fire drills and evacuation exercises as a way to rise awareness and improve fire safety.

In 1935 the behavior of vulnerable people who have gone through some kind of trial fire evacuation has been explored. Their chances of survival were much higher than those who did not have a single trial evacuation (Karabasil et al., 2014).

Fire protection system in Serbia is at very low level, especially considering its organization, competence and efficiency. Consequently, there is a rise of needs for computer evacuation models that will provide evacuation time estimation for public buildings and for buildings in general, because the prescriptive codes, generally, do not provide clear guidance. Having that in mind, nowadays, evacuation simulation models are playing an important role in the field of fire safety engineering, especially within fire safety risks assessment. The fire risk assessment should help ensuring that fire prevention measures are implemented, fire safety procedures and fire precautions, such as evacuation plans, written instructions, systems and equipment, are all in place and working properly. Also, the fire risk assessment should identify any issues that need attention.

A case study for Amphitheatres building at the Faculty of Technical Sciences (FTS) in Novi Sad and results obtained by experimental evacuation simulation could contribute in fire risk assessment process in similar buildings. The evacuation time was determined using simulation software Pathfinder, based on parameters defined by technical recommendations SRPS TP 21.

\section{BASIC DATA ON THE BUILDING}

When assessing the fire risk of buildings, it is necessary to take into account all information relevant to fire protection, such as the plan of building's infrastructures, number of floors, structural 
characteristics in terms of fire resistance, the purpose and content of the building, the applied fire protection measures, distance from the fire brigade, etc.

Faculty of technical sciences is located in central part of the University campus in Novi Sad, in Liman I city area. It consists of 7 buildings and one of them, Block of Amphitheatres, is the research subject of this paper (Fig. 1).

Access roads to the location from Professional fire-fighting-rescue unit of Novi Sad are paved roads, adequate width and capacity for movement of firefighting vehicles. Travel distance of professional fire-rescue units to the location with primary route is $4.2 \mathrm{~km}$, or the same distance in case of movement with alternative route (Fig. 2). Estimated time of arrival is 7 minutes.

The Faculty is located on flat terrain; however, in the Amphitheatre area there is depression so fire brigade intervention, in case of fire, has to be performed from a certain distance.

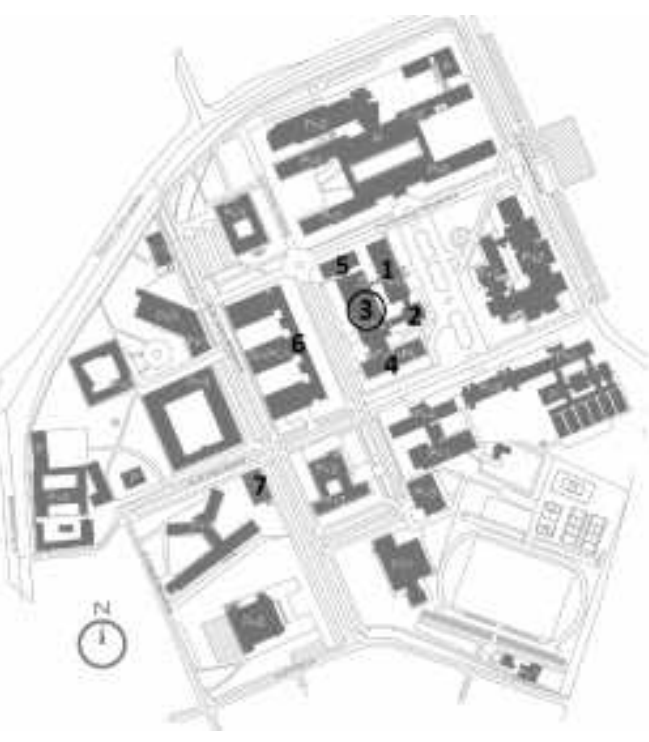

Fig. 1 University campus in Novi Sad: Location of buildings of FTS: 3- Amphitheatres

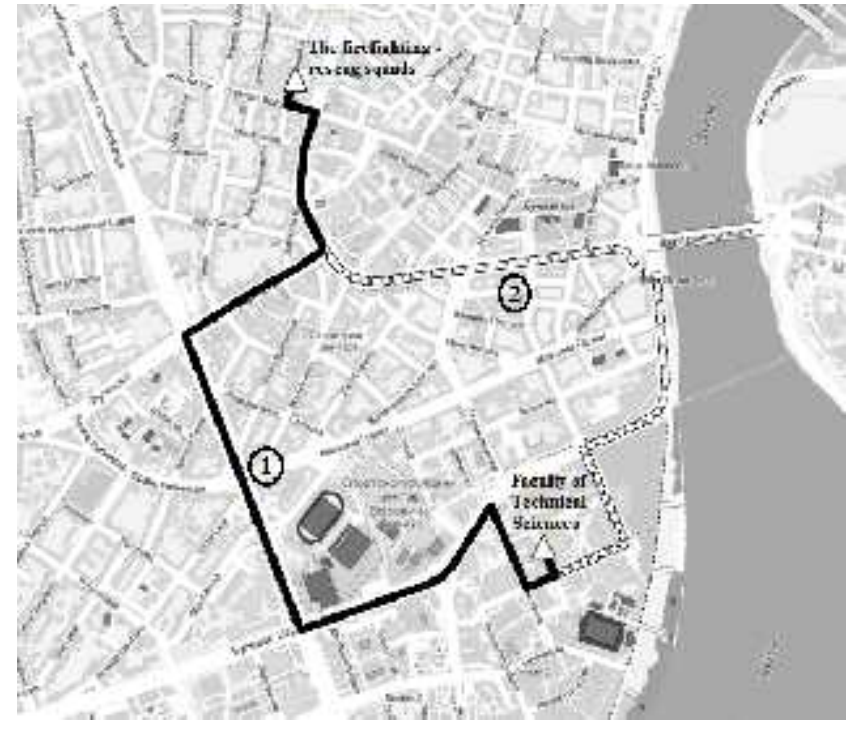

Fig. 2 Fire brigade's access roads to the location: 1-Primary route; 2-Alternative route;

FTS is a public building and is consisted of cellar, ground floor and $1^{\text {st }}$ floor. As the height of the last building's floor does not exceed $30 \mathrm{~m}$ in relation to the surrounding ground, building does not belong to the class of high-rise buildings. The main entrance (with windshield) is from the Vladimir Peric Valter Street. Block of Amphitheaters is connected with Administrative building, Teaching block, ITC and Block F by pedestrian passages (Fig. 3).

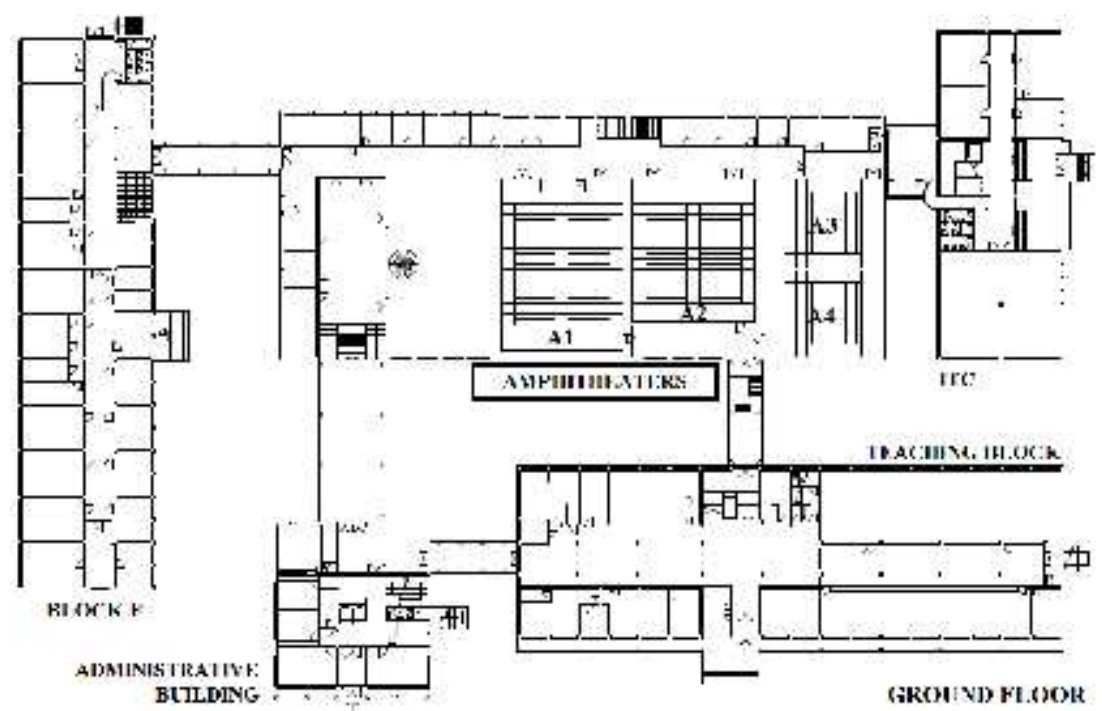

Fig. 3 Amphitheaters' connection to other FTS buildings 
The load-bearing structure is made of reinforced concrete (in further text: RC) and RC canvas for stiffening of structure. The exterior walls are plastered and made of brick. The roof is flat, impassable. Plastered and colored interior brick walls are prevailing in the structure of partition walls, although there are subsequently built partition walls of plaster boards or lightweight wooden partitions. Windows and entrance portals are made of black metalwork with aluminum - strips and double glazing. Internal doors are wooden. Headroom is $345 \mathrm{~cm}$ height, while in amphitheaters maximum height is $740 \mathrm{~cm}$. Building vertical communications is three-way RC staircase positioned opposite to the main entrance to the building. Passages are made of RC, they are glazed and have sufficient length to prevent the fire spread from one building to another. However, in case of fire in this block, adjacent buildings would be endangered by smoke, so it is necessary to provide full opening or breaking of glazed portals, to ensure smoke extraction from evacuation routes and to prevent spread of smoke through related facilities. Corridors' floors are terrazzo floors or lined with marble slabs, while in amphitheaters, library, reading room, classroom, offices and cabinets there are parquet floors or floors made of plastic materials. The walls are plastered and painted with dispersive colors. In the amphitheaters walls are partly covered with wooden boards. Floors and walls in sanitary facilities are covered with ceramic tiles. The ceilings are plastered and painted.

Except of four amphitheaters, there are also the reception desk, bookstore, copy shop, library, offices, storage, mail, printing, office and toilets at the ground floor level; a hall with exits from the amphitheaters and offices, hall, library, copy shop and bookstore, offices at the first floor, and above the amphitheaters, there is a classroom with a capacity of 30 people. Mail, printing, bookstore and library have direct entrances / exits to the outer space. Area of complete individual floors is approx. $2040 \mathrm{~m}^{2}$, or the total surface area is $3500 \mathrm{~m}^{2}$.

The maximum number of persons who could be present in the amphitheaters (mostly students) during the fire event or some other event with catastrophic consequences is 830 , while total number of the people (with employees) who could be present in the building amounts 1200 .

\section{SIMULATION SCENARIOS}

The evacuation simulation model has been created using simulation software - Pathfinder (Fig. 4)

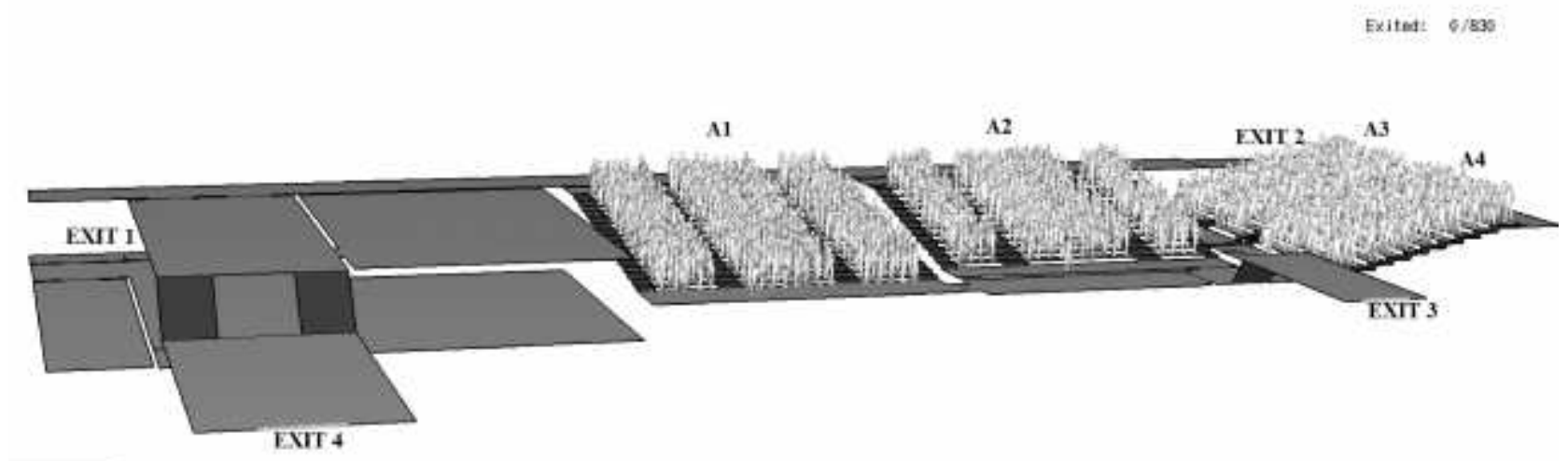

Fig. 4 Evacuation simulation model

The simulation scenarios are based on building layout and occupants' density in the case of real fire incident. Walking speeds are defined by technical recommendations SRPS TP 21.

The scenarios foresee evacuation where occupants from all amphitheatres are being activated at the same time. Model includes the maximum number of people - 830; corresponding to the seating capacity. People from other buildings are not taken into account because it is unlikely that fire will occur in all buildings at the same time.

All actors in evacuation have assigned walking speeds in interval of $1.2 \mathrm{~m} / \mathrm{s}-1.5 \mathrm{~m} / \mathrm{s}$, where walking speeds represent moving downstairs and normal walking speed, respectively. 
For the purpose of research, three different scenarios have been created, differing in the actors' exit selection and taken fire safety measures.

\subsection{Simulation scenario 1}

This simulation scenario is conditionally the worst case scenario. The evacuation of all occupants from the Amphitheaters A1 and A2 is performed through the upper exit doors, then through the hall on the ground floor level of Block, down the stairs to the hall in basement level of the building, toward the main exit of the building (Exit 1) and to the safe place (Path 1).

The evacuation of occupants from the Amphitheater A3 is performed from the exit of the amphitheater through the hall and foyer connection with the building ITC (Exit 2). ITC can be considered as a safe place if the opening in the wall that separates the two buildings is a fire and smoke proof door, and if we remove combustible materials from the passage. For now, this route is only the shortest way for escape. Evacuation path leads through the passage and then to the ITC ground floor and down the staircase in the hall to the main exit (Path 2). Due to the small capacity of the exit door of this communication, the escape route is not suitable for evacuation of people from other rooms of amphitheaters block.

The evacuation of occupants from the Amphitheater A4 is performed from the exit of the amphitheater through the hall; up to the stairs to passage that connects this block with Teaching block, then through the hall and downstairs to the ground floor of the Teaching block, down the hall to the main entrance (Exit 3, Path 3). If for any reason this exit is inaccessible, it is possible to perform evacuation by alternative path from the landing of the main staircase downwards, towards cellar and then through the hall to faculty students' club and through the club outside.

\subsection{Simulation scenario 2}

This simulation scenario represents the scenario closest to real situation evacuation. It is realistic to expect that the part of the present persons begin evacuation from amphitheaters A1 and A2 through the lower exit doors, and their evacuation route is the same as evacuation route of occupants present in amphitheater A4 (Path 3). Scenario foresees evacuation where 1/3 of actors use Path 3, while other $2 / 3$ at the beginning of evacuation use Path 1 until arrival to the staircase and then actors do not get down, but continue their evacuation through passage leading to Administrative building to its exit (Exit 4). In this case unrestricted intervention of the fire brigade would be enabled as Exit 1 stays free. Also, it can be expected that $1 / 2$ of occupants will instinctively follow actors from A1 and A2.

\subsection{Simulation scenario 3}

This simulation scenario represents conditionally the best case scenario, or improved simulation scenario 1. It is possible to significantly speed up the evacuation by opening a direct way out at basement level, to the parking lot of the Faculty. In this case, everyone present in the premises related to ground floor corridor and amphitheaters would be able to evacuate down the stairway connecting the two levels from the hallway and directly outside. Also, opening the exit to the inner yard of the building would significantly unburden an escape route, i.e. Path 3.

In this scenario, 1/3 of occupants will evacuate from amphitheaters A1 and A2 through the upper exit doors, then through the hall and down the stairs leading to the new-opened exit to the parking lot. 1/3 of occupants from these amphitheaters will take Path 1, while other occupants from A1 will evacuate through the lower exit doors and then through the new-opened exit to the inner yard of the building. Other A2 occupants, as well as occupants from amphitheater A4 during the evacuation will take Path 3. Occupants from amphitheater A3 will use Path 2 to reach exit.

\section{$4 \quad$ RESULTS DISCUSSION}

Total times required to evacuate all persons from the amphitheatres, obtained by computer model and based on chosen simulation scenario are following:

- Simulation scenario $1: 5 \min 9 \mathrm{~s}$ 
- Simulation scenario 2: $4 \min 5 \mathrm{~s}$

- Simulation scenario 3: 3 min 28s

Analysing evacuation flow in simulation scenario 1, it can be noticed that while exiting through the upper amphitheaters' door, bottlenecks appear, as well as queuing of occupants in the hall on the first floor (Fig. 5). This indicates the need for disburdening of Path 1. Total time required for evacuation of all persons, obtained by this scenario, amounts $5 \mathrm{~min} 9 \mathrm{~s}$.

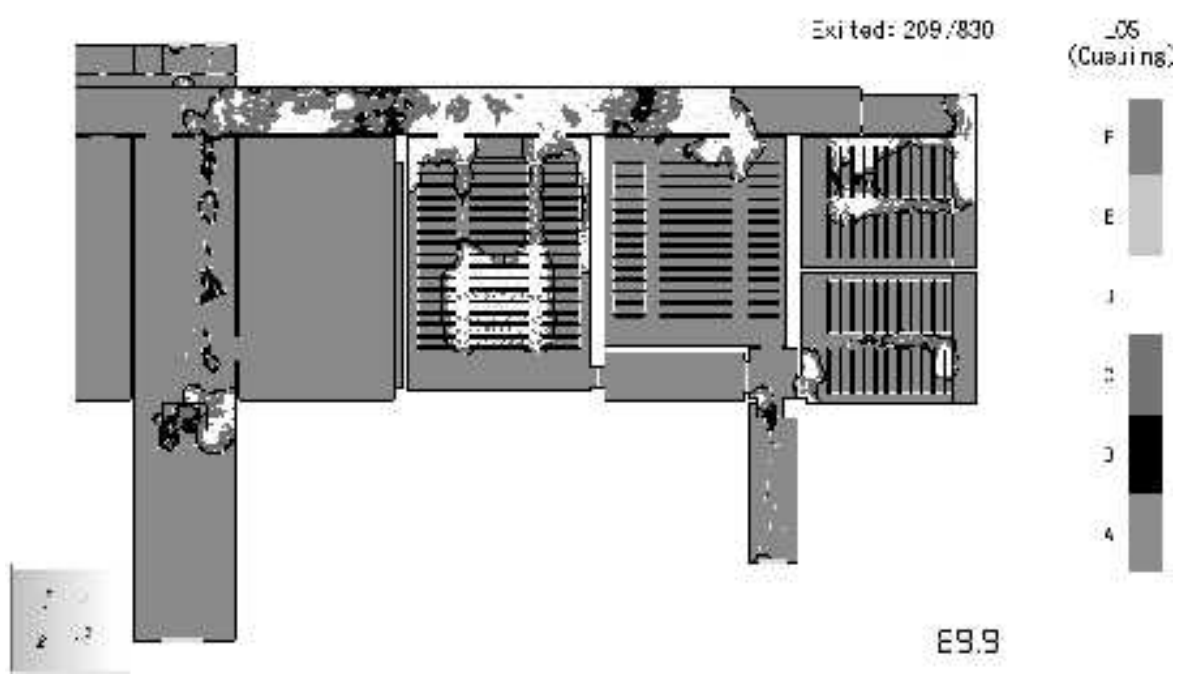

Fig. 5 Simulation scenario 1: Queuing of occupants in the hall above amphitheatres

Implementation of proper organizational measures predicted with simulation scenario 2 could reduce evacuation time. This demands all employees to know their role in the fire event, to know who should try to extinguish the fire, who directs a human stream towards the evacuation exit, who directs people away from the building, etc. Total time required for evacuation of all persons, obtained by this scenario, amounts $4 \mathrm{~min} 5 \mathrm{~s}$. Disburdening the doors lead to reduction of the evacuation time. Queuing of people in the halls is still present, however in a much lesser extent compared to the previous scenario (Fig. 6).

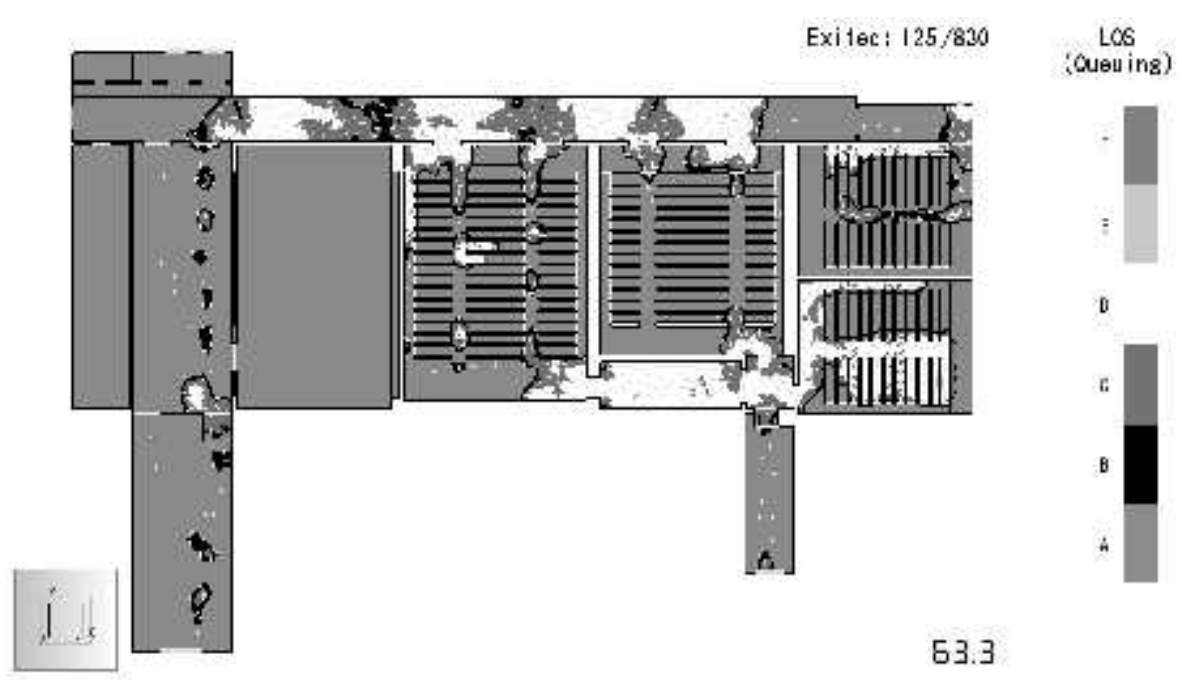

Fig. 6 Simulation scenario 2: Reduced evacuation time due to disburdening the doors

Implementation of proper technical measures predicted with simulation scenario 3 could significantly reduce evacuation time regard to both previous scenarios. Opening of the new exit door will also disburden evacuation corridors (Fig. 7). This, of course, also requires the application of appropriate organizational measures. Total time required for evacuation of all persons, obtained by this scenario, amounts 3 min $28 \mathrm{~s}$. 


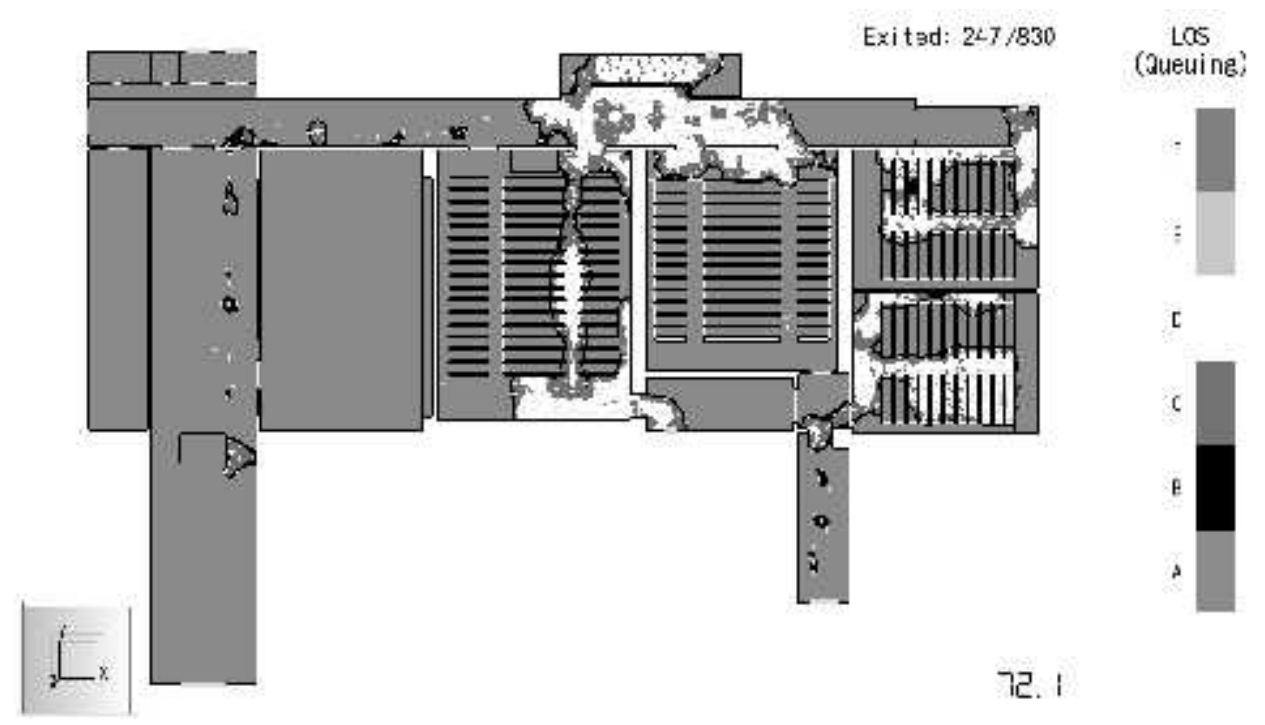

Fig. 7 Simulation scenario 3: Disburdening of corridors and reducing of evacuation time by opening a new exits

\section{CONCLUSIONS}

The time required for evacuation of all persons who could be present in the building during a fire event depends on a number of factors, some of which are very difficult to predict. In order to achieve more realistic evaluation of the evacuation process, engineers are increasingly turning towards evacuation computer models.

Evacuation simulation models could provide valuable information about the buildings' fire safety. Three different scenarios were analysed: the worst-case scenario and other two scenarios as its improved version gave the directions to act. Organizational measures - fire drills - should improve the occupants' awareness, and technical measures could improve the efficiency of evacuation process. In both improved version of simulation scenario evacuation time was reduced. It leads us to the conclusion that, besides taken technical measures, education and regular drills for staff and students, training and preparing them for real fire event would increase their chances of survival.

Simulation evacuation models enable the development and analysis of multiple scenarios of events. Based on these scenarios, adequate evacuation routes can be defined, as well as fire protection measures that could be afterwards implemented.

\section{ACKNOWLEDGMENTS}

The work reported in this paper is a part of the investigation within the research project „Improvement of processes and methods of academic education and research in computer science and automation", supported by the Department of Computing and Control Engineering, Faculty of Technical Sciences in Novi Sad. This support is gratefully acknowledged.

\section{REFERENCES}

Helsloot I., Jong W., 2006. Risk Management in Higher Education and Research in the Netherlands, Journal of Contingencies and Crises Management, Volume 14, Number 3, p. 142-159

Karabasil D., Milanko V., 2014. Behaviour of people in the evacuation during a fire (in serbian), in $1 s t$ Regional International Conference on Applied protection and its trends, 17-19 September 2014, Zlatibor, Serbia, p.209-218

SRPS TP 21: Technical recommendations for urban and civil engineering measures of fire safety for residential, commercial and public buildings, 2003, Belgrade, Serbia 